\title{
ENXERTIA EM CITROS POR SUBSTITUIÇÃO DE ÁPICE CAULINAR ${ }^{1}$
}

\author{
INEZ VILAR DE MORAIS OLIVEIRA², CARLOS FERREIRA DAMIÃO FILHO, SÉRGIO ALVES DE CARVALHO4.
}

RESUMO - O objetivo do presente trabalho foi o de verificar o pegamento de pequenos ápices caulinares (enxertos) da cultivar de laranjeira'Valência', enxertados sobre plântulas de cinco porta-enxertos: Limão- 'Cravo'; Citrange-'Troyer'; Tangerina- 'Cleópatra'; Trifoliata-'Davis A' e Citrumelo'Swingle'. Os enxertos consistiram de porções apicais do caule, com 2-3 mm de espessura. Os porta-enxertos, aos 70 dias após a semeadura, foram seccionados transversalmente abaixo do ponto de inserção do primeiro eófilo, com altura variando de 13,4 a 17,6 mm acima do nível do substrato. Os ápices meristemáticos isolados foram colocados sobre a superfície cortada dos caules e aderidos entre si por meio de parafilme (Parafilmâ ®). Aos 45 dias após a enxertia, verificou-se o "pegamento” médio de 79\%; 67\%; 66\%; 61\% e 34\% nos porta-enxertos 'Cravo', 'Troyer', 'Cleópatra', Trifoliata 'Davis A' e Citrumelo- 'Swingle', respectivamente. Aos 45 dias após a enxertia, o número médio de folhas emitidas pelos ápices caulinares enxertados foi de 3,9 e 2,2 sobre 'Cravo' e 'Cleópatra', respectivamente. Foram descritos e documentados aspectos morfológicos e anatômicos da região de contato entre enxerto e porta-enxerto.

Termos para indexação: enxertia precoce, microenxertia ex vitro, porta-enxerto.

\section{CITRUS BUDDING BY SHOOT APEX REPLACEMENT}

ABSTRACT - This work aimed to verify the setting of small shoot scions of 'Valência' orange tree, inserted on seedlings of five stocks: Rangpur Lime; Citrange 'Troyer'; 'Cleópatra' Mandarin; Trifoliata 'Davis A' and Citrumelo 'Swingle'. The scions consisted of stem apical segments with 2-3 $\mathrm{mm}$ thickness. Seventy days after sowing, the stock seedlings were cut, transversely, below the node of the first true leaf at the height ranging from 13,4 to 17,6 mm above the substrate level. The meristematic apices were put on the cut surface of the stocks and fixed with plastic film (Parafilmâ $\circledR$ ). Forty five days after budding, the percentages of selling were: 79\%; 67\%; 66\%, 61\% and 34\% in 'Rangpur' Lime; 'Troyer'; 'Cleópatra'; Trifoliata 'Davis A' and Citrumelo 'Swingle', respectively. In the same date, the number of leaves emitted by the scions was 3,9 and 2,2 in 'Rangpur' Lime and 'Cleópatra', respectively. Morphological and anatomical aspects of the contact area between scion and stock were documented and described.

Index terms: precocius budding, ex vitro microbudding, stocks.

\section{INTRODUÇÃO}

Uma rápida e considerável mudança mundial ocorreu no sistema de produção de mudas cítricas, ora conduzido em ambiente protegido contra o ataque de insetos e em recipientes, resultando em melhor controle fitossanitário e redução no tempo de produção. De acordo com Graf (2001), o Estado de São Paulo produz atualmente 20 milhões de mudas cítricas, sendo, destas, 3,5 milhões produzidas em ambiente protegido.

A enxertia é vista como a arte de inserir uma parte de uma planta em outra planta, de tal maneira que as duas constituam uma unidade e ambas continuem seu crescimento. Thouin (citado por Bailey, 1944), na sua obra Monographie des Greffes, de 1821, descreveu 119 diferentes maneiras de proceder-se a enxertia e assinala que, para o sucesso do procedimento, há necessidade de justapor-se o tecido cambial de ambas as partes envolvidas e de proteger-se apropriadamente a região.

Com o advento da biotecnologia e das técnicas de cultura de tecidos, a prática da enxertia para a produção de propágulos, além da mera continuidade de crescimento entre as partes envolvidas, tem por objetivo a obtenção de mudas sadias, isentas de doenças.

Na cultura dos citros, um tipo especial de enxertia foi desenvolvido para possibilitar a recuperação de meristemas apicais com tamanho variando entre 0,2 a $0,8 \mathrm{~mm}$, que não apresentam a mesma facilidade de desenvolvimento in vitro, como observado para outras culturas. Assim, além da continuidade de crescimento entre as partes envolvidas, a técnica permite a obtenção de plantas isentas de doenças sistêmicas transmissíveis normalmente pela enxertia convencional. A eficiência do processo, genericamente denominado de microenxertia, baseia-se na utilização de ápices meristemáticos (enxertos), sem a presença de vasos condutores e livres de patógenos (Navarro et al., 1975; 1976). Sua associação com tratamento térmico permite a obtenção de material livre de patógenos de difícil eliminação, como os vírus do complexo da sorose dos citros (Carvalho et al., 2000).
Com a intenção de eliminar vírus em plantas citrícas sem, entretanto, utilizar o processo de obtenção in vitro das mesmas, Takahara et al. (1986) desenvolveram um método de trabalho, denominado "semimicroenxertia". Tal método não requer condições assépticas na sua condução e associa tratamento térmico à enxertia de ápices com reduzido tamanho (0,2-0,4 mm de espessura), em "seedlings" decapitados acerca de 20-20,5 mm acima do colo. Os autores relataram sobrevivência, em campo, de 10 a $20 \%$ das mudas enxertadas e indexadas para doenças viróticas.

George \& Sherrington (1984) afirmam que "a sobrevivência dos ápices de Citrus microenxertados é dependente de seu tamanho”. Relatam que, "ainda que ápices muito pequenos tenham sido usados para a eliminação de vírus (tornando a técnica difícil ou não-realizável), ápices maiores podem ser utilizados se a microenxertia for efetuada com propósitos de propagação".

O uso de microborbulhas visando à enxertia mais precoce em citros, desde que o câmbio do porta-enxerto apresente atividade e a casca se solte facilmente, foi descrito por Wishart em 1961, conforme Platt \& Optiz (1973). O uso de técnica semelhante foi descrito recentemente, por Vijayakumari \& Singh (2000), na propagação rápida de material sadio de tangerina- 'Nagpur' em "seedlings" de seis meses de idade de limoeiros- 'Cravo' e 'Rugoso'. Conforme mencionado pelos autores, os resultados de $70 \%-80 \%$ de pegamento podem ser ainda melhorados com maior prática do operador.

O objetivo deste trabalho foi avaliar o pegamento de ápices caulinares com 2-3 mm de espessura, de laranjeira-'Valência', sobre cinco diferentes porta-enxertos, bem como o desenvolvimento inicial das plântulas formadas e os aspectos morfoanatômicos da região de contato entre as duas partes envolvidas.

\section{MATERIALEMÉTODOS}

Os trabalhos foram desenvolvidos em casa de vegetação e laboratório de Morfologia Vegetal e do Departamento de Biologia Apli-

1 (Trabalho 017/2002). Recebido: 08/01/2002. Aceito para publicação: 24/10/2002.

2 Aluna do PPG em Genética e Melhoramento de Plantas, DBAA/FCAV/UNESP, CEP 14884-900, Jaboticabal, SP, Brasil. Bolsista CAPES - fone (016) 32092620; e-mail: inezvilar@yahoo.com

3 Professor do Departamento de Biologia Aplicada à Agropecuária - FCAV/UNESP, Jaboticabal, SP, Brasil. - fone (016) 32092620; e-mail: damiao@ fcav.unesp.br 4 Pesquisador do Centro de Citricultura Silvio Moreira/IAC, C.P. 4, CEP 13490-970, Cordeirópolis, SP, Brasil. - fone (019) 5461399; e-mail: sergio@ centrodecitricultura 
cada à Agropecuária, da Faculdade de Ciências Agrárias e Veterinárias (FCAV/UNESP) Câmpus de Jaboticabal-SP, no período de junho a novembro de 2001.

O material vegetal para a enxertia consistiu de gemas caulinares apicais excisadas de da laranjeira-'Valência' (Citrus sinensis L. Osbeck), retiradas manualmente com o auxílio de lâmina de barbear. As gemas caulinares, com espessura de 2-3 mm (Figura 1), foram provenientes de ramos coletados de plantas da Estação Experimental de Citricultura de Bebedouro-SP.

Os porta-enxertos foram obtidos pela germinação de sementes das variedades de porta-enxertos: Limoeiro- 'Cravo' (Citrus limonia Osb.), Tangerina- 'Cleópatra' (Citrus reshni Hort. Ex Tan), Trifoliata'Davis A' (Poncirus trifoliata Raf.), Citrange-'Troyer' (C. sinensis x $P$. trifoliata, e Citrumelo-'Swingle' (C. paradisi Macf. x $P$. trifoliata) coletadas de plantas-matrizes do Centro de Citricultura Silvio Moreira/ IAC/Cordeirópolis-SP.

O experimento foi montado em delineamento experimental inteiramente casualizado, com cinco tratamentos, representados pelos porta-enxertos. Cada tratamento foi repetido seis vezes e cada parcela possuía 16 plântulas. Os dados obtidos foram submetidos a análise de variância, e as médias comparadas pela aplicação do teste de Tukey, a $5 \%$ de probabilidade.

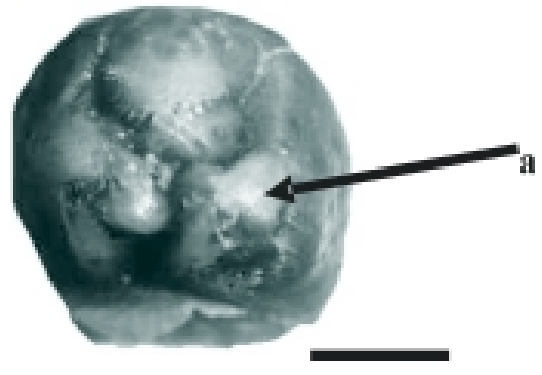

FIGURA 1 - Vista da gema apical, da cultivar de laranja-'Valência', utilizada como enxerto; a) primórdios foliares. Escala $=1 \mathrm{~mm}$

A semeadura foi realizada em junho de 2001, em tubetes plásticos contendo substrato comercial à base de casca de pínus e vermiculita (Plantmax $\left.{ }^{\circledR}\right)$. Antes de efetuar-se a enxertia, quando as plântulas se encontravam com 3 a 4 primórdios foliares (aproximadamente 60 dias após a semeadura), as mesmas foram transplantadas para sacolas plásticas com capacidade de um litro, contendo mistura de terra, areia e composto orgânico na proporção 1:1:1.

Aos 70 dias após a semeadura dos porta-enxertos, as plântulas foram submetidas a análise de dados biométricos (altura das plântulas, número de folhas, diâmetros dos caules e alturas dos cortes nos portaenxertos), conduzidas para laboratório, e com auxílio de lâmina de barbear, foram submetidas a corte transversal do caule abaixo do primeiro eófilo, eliminando-se a parte aérea.

Imediatamente após a excisão dos ápices caulinares, os mesmos foram manualmente transferidos para a região do corte dos portaenxertos, sendo ambas as partes unidas entre si por meio de filme plástico (Parafilm ${ }^{\circledR} \mathrm{M}$ ), conforme pode ser observado na Figura 2.

Aos 45 dias após a enxertia, determinou-se a percentagem de ápices caulinares que emitiram parte aérea ("pegamento"), as alturas das novas plântulas formadas e o número de folhas emitidas pelo enxerto.

Também aos 45 dias após a enxertia, três plântulas representativas de cada tratamento foram selecionadas para proceder-se a análises histológicas e anatômicas. As amostras consistiram da porção apical do caule, englobando uma parte do caule dos porta-enxertos e as novas partes aéreas formadas. Após permanecerem uma semana em solução fixadora, as amostras foram submetidas ao processo de preparação de lâminas histológicas permanentes, de acordo com Johansen (1940). As amostras de tecidos foram fotomicrografadas em microscópio óptico, sendo os resultados analisados e discutidos.

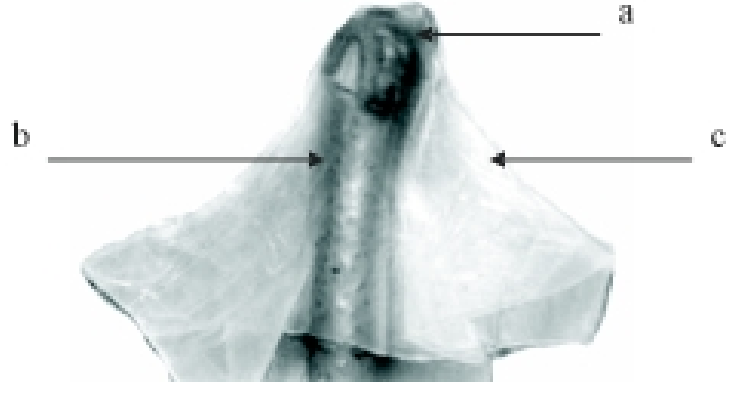

FIGURA 2 - Vista longitudinal do enxerto da laranjeira- 'Valência' (a), sobre o porta-enxerto (b), unidos por meio da aplicação de filme plástico (Parafilm $\left.{ }^{\circledR} \mathrm{M}\right)(\mathrm{c})$.

\section{RESULTADOSE DISCUSSÃO}

Dados biométricos dos porta-enxertos (tratamentos), por ocasião da enxertia, podem ser observados na Tabela 1.

A análise dos resultados expressos na Tabela 1 permite verificar que, por ocasião da enxertia, as plântulas do porta-enxerto Trifoliata'Davis A' apresentavam-se comparativamente com caules de maior diâmetro e com maior altura média, indicando maior vigor vegetativo, nesta fase de crescimento. Sob outro aspecto, o Limoeiro- 'Cravo' e o Citrange'Troyer' apresentaram as maiores alturas quanto ao ponto de corte dos caules (altura da enxertia). De acordo com a metodologia empregada, as maiores alturas de corte, do colo até o ponto da enxertia, facilitam a operação de colocação do enxerto.

Apesar de a cultivar Citrumelo 'Swingle' diferir significativamente das demais, sendo superior quanto ao número médio de folhas por ocasião da enxertia, tal parâmetro (número de folhas) parece ser um bom indicativo da fase de crescimento na qual deva ser realizada a operação de enxertia, ou seja, quando as plântulas apresentam entre 5-6 eófilos, o que ocorreu para todas as outras cultivares, que não diferiram estatisticamente entre si neste aspecto.

TABELA 1 - Valores médios para os dados de diâmetro do caule, altura das plântulas, número de folhas e altura da enxertia dos diferentes porta-enxertos avaliados, por ocasião da enxertia.

\begin{tabular}{ccccc}
\hline TRATAMENTOS & $\begin{array}{c}\text { Diâmetro do } \\
\text { caule }(\mathrm{cm})\end{array}$ & $\begin{array}{c}\text { Altura de } \\
\text { Plântulas (cm) }\end{array}$ & $\begin{array}{c}\text { Número de } \\
\text { Folhas }\end{array}$ & $\begin{array}{c}\text { Altura da } \\
\text { Enxertia (cm) }\end{array}$ \\
\hline Cravo & $1,54 \mathrm{c}^{*}$ & $4,31 \mathrm{~d}$ & $5,20 \mathrm{~b}$ & $1,76 \mathrm{a}$ \\
Troyer & $1,78 \mathrm{~b}$ & $4,90 \mathrm{c}$ & $5,50 \mathrm{~b}$ & $1,43 \mathrm{ab}$ \\
'Cleópatra' & $1,21 \mathrm{~d}$ & $3,60 \mathrm{e}$ & $5,15 \mathrm{~b}$ & $1,34 \mathrm{~b}$ \\
Trifoliata- 'Davis'A & $2,06 \mathrm{a}$ & $6,09 \mathrm{a}$ & $5,35 \mathrm{~b}$ & $1,55 \mathrm{ab}$ \\
Citrumelo - 'Swingle' & $1,61 \mathrm{c}$ & $5,45 \mathrm{~b}$ & $6,27 \mathrm{a}$ & $1,66 \mathrm{ab}$ \\
\hline C.V.(\%) & 3,55 & 6,22 & 4,91 & 14,31 \\
\hline
\end{tabular}

"Em cada coluna, médias seguidas de mesma letra não diferem significativamente, pelo teste de Tukey, a 5\% de probabilidade; C.V. = coeficiente de variação.

Na Tabela 2, são apresentados dados biométricos das plântulas enxertadas, aos 45 dias após a realização dos enxertos.

Com relação a "pegamento" dos enxertos, verifica-se que os maiores índices foram obtidos para o Limoeiro- 'Cravo', o Citrange'Troyer' e a Tangerina- 'Cleópatra', que foram superiores ao Citrumelo'Swingle', mas não diferiram do Trifoliata- 'Davis A'.

De maneira geral, verifica-se que o procedimento proposto para a enxertia de citros, por substituição do ápice caulinar, é efetivo, promovendo a união do enxerto aos porta-enxertos utilizados e a continuidade do crescimento de ambos. As diferenças observadas nas percentagens de "pegamento" podem estar relacionadas ao maior ou menor grau de compatibilidade entre enxerto e porta-enxertos testados.

A altura de plantas não diferiu entre os porta-enxertos, enquanto o número de folhas emitidas com o uso do limoeiro- 'Cravo' e Citrange- 'Troyer' tendeu a ser maior, e 'Cleópatra' e Citrumelo os meno- 
res.

Analisando-se de maneira geral os resultados expressos na Tabela 2, constata-se que as alturas médias das plântulas, aos 45 dias após a enxertia, é uma determinação que não reflete, adequadamente, o efeito dos tratamentos, visto as mesmas não apresentarem, estatisticamente, diferenças entre si.

Com relação às percentagens de "pegamento" e ao número de folhas emitidas, entretanto, tais parâmetros indicam marcante superioridade do Limoeiro- 'Cravo', em números absolutos. No extremo oposto, encontra-se o porta-enxerto Citrumelo- 'Swingle', que mostrou a menor percentagem absoluta de "pegamento" $(34,37 \%)$ e baixo número médio de folhas $(2,51)$ emitidas pelos enxertos que deram continuidade ao crescimento, igualando-se estatisticamente, neste último aspecto, às cultivares Tangerina- 'Cleópatra' e Trifoliata- 'Davis A'.

TABELA 2 - Valores médios da percentagem de "pegamento"; da altura das mudas, em cm e número de folhas das plântulas enxertadas nos diferentes porta-enxertos avaliados aos 45 dias após a enxertia.

\begin{tabular}{cccc}
\hline TRATAMENTOS & Pegamento (\%) & Altura das Mudas (cm) & Número de Folha \\
\hline Cravo & $79,16 \mathrm{a}^{*}$ & $2,86 \mathrm{a}$ & $3,91 \mathrm{a}$ \\
Troyer & $67,70 \mathrm{a}$ & $2,86 \mathrm{a}$ & $3,59 \mathrm{a}$ \\
'Cleópatra' & $66,66 \mathrm{a}$ & $2,60 \mathrm{a}$ & $2,29 \mathrm{~b}$ \\
Trifoliata 'Davis'A & $61,45 \mathrm{a} \mathrm{b}$ & $2,67 \mathrm{a}$ & $3,09 \mathrm{ab}$ \\
Citrumelo 'Swingle' & $34,37 \mathrm{~b}$ & $2,45 \mathrm{a}$ & $2,51 \mathrm{~b}$ \\
\hline CV(\%) & 28,13 & 15,17 & 18,59 \\
\hline
\end{tabular}

*Em cada coluna, médias seguidas de mesma letra não diferem significativamente, pelo teste de Tukey, a 5\% de probabilidade; C.V. = coeficiente de variação.

As observações histológicas das lâminas da região do enxerto, ao microscópio óptico, indicaram não haver diferenças morfológicas e anatômicas entre tratamentos, podendo-se afirmar que, neste aspecto, as cultivares porta-enxertos e enxertos uniram-se entre si de acordo com um padrão semelhante. A Figura 3 A mostra a emissão de folhas pelo enxerto e a região de união entre o porta-enxerto e enxerto, na qual foram feitos estudos anatômicos. Por sua vez, a Figura 3 B, tomada na região de união do porta-enxerto limoeiro- 'Cravo' e do enxerto da laranjeira'Valência', ilustra detalhes anatômicos e histológicos da região de união dos enxertos e porta-enxertos.

A análise da Figura 3 evidencia que, para efeito de união das partes do enxerto, não há, exatamente, necessidade de justaposição de tecidos vasculares: observa-se, na foto $3 \mathrm{~A}$, que a extremidade esquerda da base do ápice caulinar (enxerto) encontra-se deslocada para o exterior do caule do porta-enxerto; na foto $3 \mathrm{~B}$, verifica-se que o enxerto encontra-se fora da orientação da linha de continuidade do caule em ambas as direções, neste ângulo de observação. Com maior detalhe, a fotomicrografia apresentada na Figura 4 traz uma provável indicação da maneira como ocorreu a junção de tecidos vasculares entre o portaenxerto e o enxerto. A análise dos tecidos indica que, ainda que o ápice caulinar da laranjeira- 'Valência' não tenha sido completamente justaposto ao caule do porta-enxerto, os tecidos vasculares internos ordenam-se para uma solução de continuidade. Na região de contato entre ambos, ocorre proliferação de células parenquimáticas. Tais resultados são condizentes com os relatados por Dickison (2000), que afirma que o processo de soldadura de microenxertos ocorre em poucos dias e que, neste estágio inicial, há formação de células parenquimáticas na interface do enxerto, as quais preenchem a fenda no ponto da enxertia, constituindo-se em calo que associa a copa e o porta-enxerto.

Continuando-se a análise da Figura 4, verifica-se que os feixes vasculares confluem, por diferenciação específica destas células parenquimáticas de cicatrização, na superfície de ambos os cortes. Segundo Jeffree \& Yeoman (1983), a diferenciação de algumas células do calo, a partir de novas células pró-cambiais, formam uma conexão contínua de tecidos condutores, assegurando uma sistematização da vascularização entre as partes envolvidas no enxerto.
O processo, de maneira geral, foi totalmente desenvolvido em ambiente protegido, e apresenta potencialidades para a produção de mudas comerciais, ressaltando-se os aspectos referentes à rapidez (cerca de 200 enxertos/hora podem ser operacionalizados por um operador com prática) e à maior rapidez da produção de mudas, tendo em vista a precocidade da enxertia. Tais aspectos, entretanto, carecem de estudos mais detalhados, antes de sua aplicação prática.

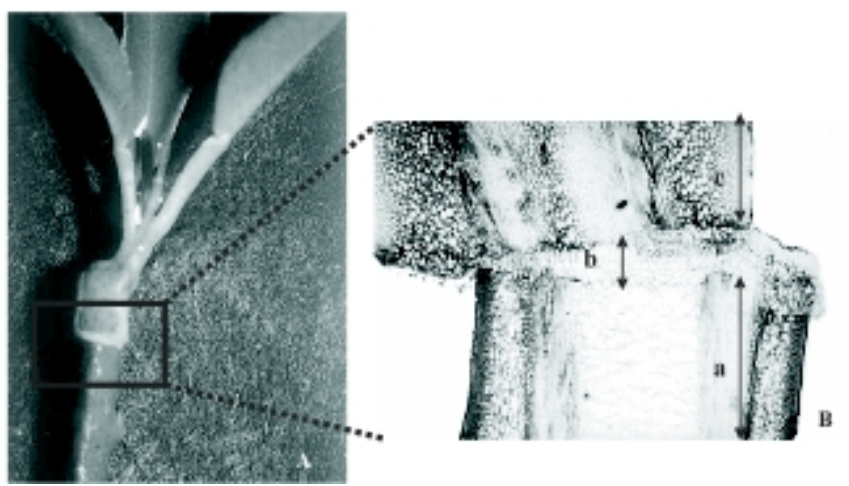

FIGURA 3 - Em A, fotomicrografia de plântula de limoeiro- 'Cravo', na qual foi enxertado o ápice caulinar da laranjeira-'Valência', evidenciando a emissão de folhas pelo enxerto; em B, fotomicrografia em microscópio óptico de idêntico tratamento ao mostrado em A, em corte longitudinal, no qual se indicam as grandes regiões pertinentes à área de união (b) entre o porta-enxerto (a) e o enxerto (c) (aumento 100x).

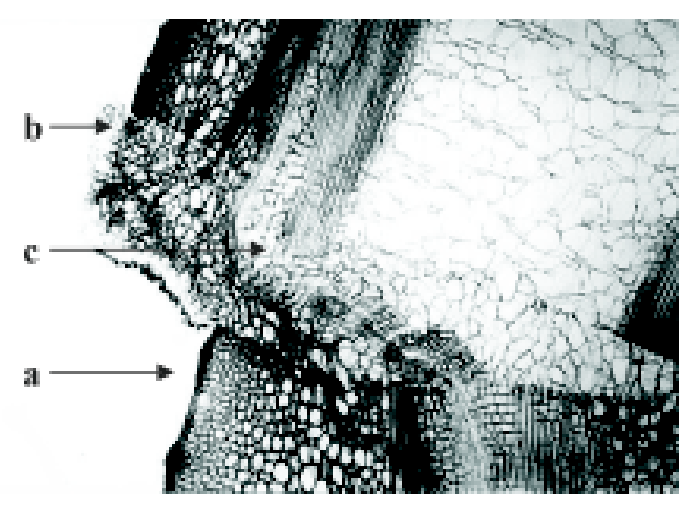

FIGURA 4 - Fotomicrografia evidenciando a região de contato entre o porta-enxerto limoeiro- 'Cravo' (a) e o enxerto (ápice caulinar) (b) da laranjeira 'Valência', sendo indicado em (c) o feixe vascular deslocando-se para a esquerda, completando a união dos mesmos, entre as partes envolvidas na enxertia (aumento 200x).

\section{CONCLUSÕES}

Nas condições descritas para a metodologia e material empregados no presente trabalho, pode-se concluir que o processo de enxertia, utilizando-se como enxerto do ápice caulinar, mostra-se efetivo e factível, em condições não axênicas, com o objetivo de produção de propágulos. Entre as cultivares de porta-enxertos testadas, sobressaiu-se o Limoeiro- 'Cravo', como suporte do ápice caulinar isolado da laranjeira'Valência'.

\section{AGRADECIMENTOS}

À CAPES, pela concessão de bolsa de estudo à Inez Vilar de Morais Oliveira; à laboratorista Roseli Conceição Silva, pela ajuda na condução do experimento. Aos professores Dr. Carlos Ruggiero e Dra. Fabíola Vitti Môro, pelas sugestões apresentadas. 


\section{REFERÊNCIASBIBLIOGRÁFICAS}

BAILEY, L.H. The standart cyclopedia of horticulture. New York: The Macmillan Co., 1944. p. 1362-1371.

CARVALHO, S.A.; MACHADO, M.A.; SANTOS, F. A. Eliminação de sorose de variedades de citros por microenxertia associada à termoterapia. 'Cravo' In: CONGRESSO BRASILEIRO DE FITOPATOLOGIA, 33, Belém, PA, agosto de 2000. Fitopatologia Brasileira, Brasília, vol.25(suplemento):442, 2000 (Resumo 603).

DICKISON, W.C. Integrative plant anatomy. Hartcourt: Academic Press, 2000.533p.

GRAF, C. C. D. Companhias Privadas na Certificação de Mudas Cítricas no Estado de São Paulo. In: International Congress of Citrus Nurserymen, $6^{\text {th }}$.Ribeirão Preto, SP. Program \& Abstracts. Bebedouro: Estação Experimental de Citricultura de Bebedouro, 2001. p. 28.

GEORGE, E.F. \& SHERRINGTON, P.D. Plant propagation by tissue culture. Eversley: Exegetics Ltd., 1984. 709p.

JEFFREE, C.E. \& YEOMAN, M.M. Development of intercellular connections between opposing cells in graft unions. New Phytologist, New York, v.93, n.4, p.491-509, 1983.
JOHANSEN, D.A. Plant microtechnique. New York: Mc Graw-Hill Book, 1940.523p.

NAVARRO, L.; ROISTACHER, C.N.; MURASHIGE, T. Improvement of shoot-tip grafting "in vitro" for virus-free citrus. J. Amer. Soc. Hort. Sci., v.100, 1975. p. 471-9.

. The citrus variety improvement program in Spain. In: CONFERENCE INTERN. ORG. CITRUS VIROL., 7, Riverside, 1976. Proceedings...Riverside, 1976. p. 198-203.

PLATT, R.G \& OPTIZ, K.W. Propagation of citrus. In: REUTHER, W. The citrus industry. Riverside, University of California, 1973. v.3, cap.1, p. 1-47.

TAKAHARA, T.; OKUDAI, N.; KUHARA, S. Elimination of citrus viruses by semi-micrografting. Kuchinotsu: Fruit Tree Research Station, 1986. p. 13-24 (Bulletin, 8).

VIJAYAKUNARI, N.; SINGH. S. Microbuding, a novel technique for multiplication of disease - free planting material and commercial citrus propagation. In: INTERNATIONAL SOCIETY OF CITRICULTURE CONGRESS 9, 2000, Orlando. Program and Abstracts ... p. 132. Abstracts n. 228 